\title{
MOTIVASI MAHASISWA BERHUBUNGAN DENGAN TINGKAT KECEMASAN MENGHADAPI TUGAS AKHIR
}

\author{
Nutrisia Nu'im Haiya ${ }^{1}$, Iwan Ardian' ${ }^{2}$ Iqbal Gadafi $^{3}$ \\ 1,2,3 Universitas Islam Sultan Agung, Program Studi Ilmu Keperawatan \\ E-mail: Nutrisia.UNISSULA@gmail.com
}

\begin{abstract}
ABSTRAK
LatarBelakang: Motivasi pada mahasiswa mempunyai dampak negatif dan dampak positif terhadap kegiatan mahasiswa tersebut, dampak positifnya akan melakukan kegiatan dengan penuh semangat akan tetapi dampak negatifnya akan mengakibatkan kecemasan. Kecemasan adalah sesuatu yang dirasakan seperti kebingungan, rasa takut, rasa yang tidak menentu dan tidak berdaya serta kegelisahan. Penelitian ini bertujuan untuk mengetahui hubungan motivasi dengan kecemasan mahasiswa menghadapi tugas akhir.Metode:Penelitian ini merupakan jenis penelitian survei analitik dengan studi crosssectional. Pengumpulan data dilakukan dengan kuesioner. Jumlah responden sebanyak 94 mahasiswa dengan tehnik Total Sampling.Data yang diperoleh diolah secara statistik dengan menggunakan Spearmen.Hasil:Hasil didapatkan bahwa ada hubungan signifikan antara motivasi dengan kecemasan pada mahasiswa tingkat akhir $(p=0,0009)$ dengan $r=0,270$.Simpulan : motivasi mahasiswa berhubungan dengan tingkat kecemasan yang sedang dihadapi oleh mahasiswa tingkat akhir.
\end{abstract}

Kata Kunci : Motivasi;kecemasan; mahasiswa

\section{THE RELATIONSHIP BETWEEN MOTIVATION AND ANXIETY IN COMPILING FINAL PROJECT FOR STUDENTS}

\begin{abstract}
Background: Motivation to students has a negative impact and positive impact on the student activity, the positive impact will be doing the activities with graeat enthusiasm but negative impact will cause anxiety. Anxiety is something that feels like confusion, fear, uncertainty and helplessness and anxiety. This studied aims to determine the relationship of motivation with studens anxiety face the final task.Methods: This research was a type of research of analytic survey with cross sectional study. The data were collected by questionnaire. The number of respondents were 94 students with Total Sampling technique. The obtained data was processed statistically by used Spearmen.Results:The finded was obtained that there was a significant relationship between anxiety level and student motivation $(p=0.0009)$ with $r=0,270$.Conclusion: There was an anxiety level relationship with the student motivation.
\end{abstract}

Keywords: Motivation, Anxiety, student. 


\section{Pendahuluan}

Seorang mahasiswa mempunyai kekuatan mental sebagai penggerak, dan kekuatan mental yang digunakan sebagai pendorong mahasiswa belajar merupakan motivasi belajar. Sebagai penggerak mahasiswa dalam menimbulkan keinginan dan kemampuan untuk memperoleh hasil atau prestasi akademik yang baik, tujuan yang hendak ingin dicapai lebih terarah, serta penyeleksi perbuatan yang dapat bermanfaat bagi mahasiswa tersebut. Ada pula kondisi jiwa yang pada umumnya berpengaruh negatif terhadap motivasi, yaitu kondisi kejiwaan yang tidak stabil seperti : cemas, takut, stress, gugup dan sebagainya (Sardiman, 2011 \& Gunarsa, 2008).

Gangguan cemas sering kali dijumpai pada anak maupun remaja. Berupa kondisi yang ditandai dengan kekhawatiran dan kecemasan. Studi di Amerika menyebutkan bahwa 6,8 juta remaja berusia 18 tahun di Amerika ( 3,1\% ) mengalami kecemasan keseluruhan. Di Indonesia sendiri lebih tinggi dari pada Amerika, Indonesia mencapai 6,7\%. Menurut data Nasional comorbidity survey prevalensi kecemasan pada laki-laki $2 \%$ lebih rendah dari pada perempuan 4,3\%. Perempuan lebih banyak mengalami kecemasan pada rentang usia 16-40 tahun (Cheryl, 2010).

Mahasiswa yang mempunyai motivasi akan mengurangi tingkat kecemasan bahkan mahasiswa yang mempunyai motivasi sangat baik tidak akan mengalami kecemasan sedangkan mahasiswa yang tidak memiliki motivasi akan meningkatkan kecemasan berat ataupun panik bahkan mahasiswa yang tidak memiliki motivasi sehari-harinya akan merasa bingung dan kwatir tentang kegiatan yang akan dilakukan (Slameto, 2010).

Setiap manusia membutuhkan motivasi dalam hidupnya, meskipun jenis dantingkatanya tidak sama. Tanpa adanya motivasi tentu manusia tidak akan berbuat apa-apa, karena motivasilah yang menggerakan tingkah laku manusia. Salah satu motivasi yang ada pada diri manusia adalah dorongan untuk sukses atau berhasil. Dorongan semacam ini harus terdapat pada mahasiswa yang sedang menjalani tugas akhir, yang bertujuan menurunkan kecemasan yang dihadapi mahasiswa saat menjalani tugas akhir (Ferry, 2015).

Salah satu faktornya ada dari dalam diri dan kondisi jiwa ini ada yang dapat berpengaruh positif terhadap motivasi seperti: rasa tak puas, rasa senang belajar, penasaran, selalu ingin mencoba, selalu ingin tahu dan lain-lain. Ada pula kondisi jiwa yang pada umumnya 
berpengaruh negatif terhadap motivasi, yaitu kondisi kejiwaan yang tidak stabil seperti : cemas, takut, stress, gugup dan sebagainya (Gunarsa, 2008). Sehingga dengan penelitian ini dapat dijadikan dasar sebagai pertimbangan untuk mementukan metode atau pendekatan yang sesuai pada mahasiswa yang sedang menyelesaikan tugas akhir program studi, khususnya sarjana keperawatan.

\section{Tinjauan Teoritis}

Motivasi adalah proses perubahan perilaku seseorang yang ditandai dengan reaksi untuk mencapai sebuah tujuan (Hamalik, 2011).Ciri-ciri motivasi yang cukup tinggi dapat menimbulkan ketenangan dan ketekunan dalam belajar mengerjakan tugas, tidak mudah putus asa jika menemui kesulitan, dapat memecahkan masalah dan ingin memecahkan berbagai masalah yang ada, senang bekerja mandiri, dapat mempertahankan pendapatnya, dan tidak mudah menyerah dalam hal yang diyakini itu benar. Ciri-ciri motivasi dapat diukur dari tekad yang kuat dalam dirinya untuk belajar, berhasil, dan optimis meraih cita-cita masa depan, adanya motivasi belajar juga dapat didorong adanya penghargaan, kegiatan yang menarik, dan lingkungan yang kondusif. Individu yang memiliki motivasi yang tinggi tak lepas adanya semangat yang tinggi mempunyai rasa keingintauan yang tinggi dan bisa dikatakan memiliki motivasi yang cukup tinggi (Sardirman, 2011).

Kecemasan yaitu suatu gangguan perasaan yang di tandai oleh rasa kehilangan, kekhawatiran dan ketakutan yang mendalam, perilaku dapat berubah namun masih dalam batas normal, tidak mengalami gangguan dalam menilai realitas(Hawari, 2011).Kecemasan menghadapi tugas akhir seperti gelisah sebagai ketidaksanggupan menghadapi masalah ataupun adanya perasaan tidak aman dan reaksi umum. Perasaan berkepanjangan individu dari khawatir dan takut tanpa adanya alasan apapun, perasaan yang tidak biasa/ tidak menyenangkan dapat mengakibatkan gejala seperti ( berkeringat, gemeteran, jantung semakin cepat berdetak, bingung, menurunya tingkat berkosentrasi, panik dan sebagainya (Taylor, 2010).

Viedback (2008) membagi beberapa tingkat kecemasan yaitu; 1)Kecemasan Ringan, Kecemasan ringan dapat dilihat dari individunya dan dapat mengakibatkan individu menjadi waspada dan memperluas pikirannya. Kecemasan ringan dapat memotivasi individu dapat berkreatif lagi, Tanda-tanda pada kecemasan ringan ini adalah masih dapat belajar, kesadaran tinggi, kelelahan, konsentrasi penuh pada masalah dan tingkah laku sesuai situasi 
menyelesaikan masalah secara efektif dan baik. 2) Kecemasan Sedang, kecemasan sedang itu masih dapat memusatkan pada suatu masalah yang selektif, namun masih dapat melakuan segala hal yang terarah. Tanda-tanda pada tingkat ini bisa dilihat yaitu pernafasan meningkat, kelelahan meningkat, bicara dengan volume tinggi dan cepat, denyut jantung dan nadi cepat, ketagangan otot meningkat, tidak sabar, mudah lupa, mudah tersinggung, cara berfikir yang menyempit,susah tidur, konsetrasi sedikit menurun, menangis dan marah. 3) Kecemasan Berat,kecemasan berat ini dapat menyempitkan persepsi atau pikiran seseorang. Dengan kecemasan berat ini seseorang memusatkan pada masalah kecil dan mengabaikan masalah besar sehingga tidak mampu menyelesaikan. Tanda-tanda yang bisa dilihat adalah sakit kepala, blocking, mengeluh pusing, perasaan ancaman meningkat, dan tidak mampu belajar secara efektif. 4) Kecemasan panik, kecemasan panik dapat terperangah,teror dan ketakutan, lahan persepsi terganggu sehingga tidak dapat mengendalikan diri. Karena kehilangan kendali, individu dengan mengalami kecemasan panik ini tidak dapat terarah dapat menyebabkan tingkah laku yang tidak jelas, berteriak-teriak, sesak dada, marah, dan tidak bisa bersosialisai dengan lingkungan sekitar dan takut, pemikirannya yang menyimpang. Kehilangan pemikiran yang logis/ rasional. Pada kecemasan ini tidak sesuai dengan keseharian, jika ini dibiarkan dengan waktu sangat lama dapat menimbulkan kehilangan kendali atau kekacauan.

\section{Metode}

Penelitian dilakukan pada bulan September - November 2017 di FIK UNISSULA dengan responden mahasiswa tingkat akhir Program Studi Sarjana Keperawatan. Jenis desain yang digunakan survey analitik dengan pendekatan cross sectional point time approach. Artinya, peneliti hanya melakukan observasi saja dalam satu waktu dan satu kali saja.Analisa data menggunakan uji statistic nonparametrik (Uji Spearman). Alat ukur kecemasan menggunakan HRSA-A Hamilton Rating Scale Anxiety adalah suatu alat untuk mengukur keseriusan dan parahnya dari gejala kecemasan (anxiety) pada seseorang, dan untuk instrument motivasi menggunakan quesioner dengan 20 pertanyaan yang bersifat tertutup.

Skala pertanyaan ini digunakan untuk mengetahui sejauh mana seseorang memotivasi diri sendiri. Jumlah atau Hasil skor maksimum untuk skala pengukuran ini adalah 80. Uji validitas dilakukan pada 30 mahasiswa dengan nilai validitas $0,388-0,737$ lebih besar dari r(tabel) yaitu 
0,361 dengan jumlah responden 30 mahasiswa. Uji reabilitas dengan menggunakan rumus Alpha Cronbach dengan nilai reabilitas 0,915 lebih besar dari r(tabel).

\section{Hasil}

Hasil dari analisis univariat kemudian dilakukan analisa hubungan antara motivasi dengan kecemasan pada mahasiswa tingkat akhir di Fakultas Ilmu Keperawatan Universitas Islam Sultan Agung dengan hasil sebagai berikut:

Tabel 1. Distribusi Responden Berdasarkan Kecemasan Mahasiswa (n=94)

\begin{tabular}{lcc}
\hline \multicolumn{1}{c}{ Kecemasan } & Jumlah $(\mathbf{n})$ & Prosentase (n) \\
\hline Tidak cemas & $\mathbf{5 0}$ & $\mathbf{5 3 . 2}$ \\
Cemas ringan & $\mathbf{3 6}$ & $\mathbf{3 8 . 3}$ \\
Cemas sedang & $\mathbf{8}$ & $\mathbf{8 . 5}$ \\
\hline \multicolumn{1}{c}{ Total } & $\mathbf{9 4}$ & $\mathbf{1 0 0 . 0}$ \\
\hline
\end{tabular}

Tabel 1. Hasil penelitian menunjukkan kecemasan mahasiswa dengan tingkat kecemasan kategori tidak cemas 50 responden $(53,2 \%)$, cemas ringan 36 responden (38.3\%), cemas sedang 8 responden $(8.5 \%)$, cemas berat 0 responden (tidak ada), dan cemas sangat berat 0 responden (tidak ada).

Tabel 2. Distribusi Responden Berdasarkan Motivasi Mahasiswa (n=94)

\begin{tabular}{lll}
\hline Motivasi & Jumlah (n) & Prosentase (\%) \\
\hline Baik & 53 & 56.4 \\
Cukup & 41 & 43.6 \\
& & \\
\hline Total & 94 & 100.0 \\
\hline
\end{tabular}

Tabel 2. Hasil penelitian memperlihatkan motivasi mahasiswa dengan kategori baik dengan jumlah 53 responden $(56.4 \%)$, cukup 41 responden $(43,6 \%)$ dan buruk sebanyak 0 responden $(0 \%)$.

Tabel 3. Tabulasi Responden Berdasarkadan Motivasi dan Kecemasan ( $n=94)$

\begin{tabular}{lccccccccc}
\hline Motivasi & $\begin{array}{l}\text { Tidak } \\
\text { cemas } \\
(\mathrm{n})\end{array}$ & $\begin{array}{l}\text { Prosentas } \\
\mathrm{e}(\%)\end{array}$ & $\begin{array}{l}\text { Cemas } \\
\text { ringan } \\
(\mathrm{n})\end{array}$ & $\begin{array}{l}\text { Prosentas } \\
\mathrm{e}(\%)\end{array}$ & $\begin{array}{l}\text { Cemas } \\
\text { sedang } \\
(\mathrm{n})\end{array}$ & $\begin{array}{l}\text { Prosentas } \\
\mathrm{e}(\%)\end{array}$ & $\begin{array}{l}\text { Cemas } \\
\text { berat }\end{array}$ & $\begin{array}{l}\text { Cemas } \\
\text { sangat } \\
\text { berat }\end{array}$ & $\begin{array}{l}\text { Total } \\
\text { Baik }\end{array}$ \\
\hline 35 & $66 \%$ & 14 & $26 \%$ & 4 & $7 \%$ & 0 & 0 & 53 \\
Cukup & 15 & $36 \%$ & 22 & $53 \%$ & 4 & $9 \%$ & 0 & 0 & 41 \\
Total & 50 & & 36 & & 8 & & & & 94 \\
\hline
\end{tabular}


Tabel 3. Menunjukkan mahasiswa dengan motivasi dan tingkat kecemasannya, dengan kategori motivasi baik dan tidak cemas 35 responden (66\%), motivasi baik dan cemas ringan 14 responden (26\%), motivasi baik dan cemas sedang 4 responden (7\%), motivasi baik dan cemas berat maupun sangat berat 0 responden $(0 \%)$ atau tidak ada. Sedangkan untuk kategori motivasi cukup dan tidak cemas 15 responden (36\%), motivasi cukup dan cemas ringan 22 responden (53\%), motivasi cukup dan cemas sedang 4 responden (9\%) sedangkan motivasi cukup dan cemas berat dan sangat berat 0 responden $(0 \%)$ atau tidak ada.

Tabel 4. Uji spearman dan tabulasi Hubungan antara Motivasi dengan Kecemasan pada mahasiswa tingkat akhir $(n=94)$

\begin{tabular}{ll}
\hline & Kecemasan \\
\hline Motivasi & $\mathrm{r}=0,270$ \\
& $\mathrm{p}=0,0009$ \\
$\mathrm{n}=94$
\end{tabular}

Tabel 4. Uji spearman didapatkan data bahwa ada hubungan antara motivasi dengan kecemasan mahasiswa tingkat akhir di Fakultas Ilmu Keperawatan S1 Keperawatan di Universitas Islam Sultan Agung Semarang dengan melihat nilai p-value atau Sig. yaitu 0,009 atau $p$-value $<0,05 \mathrm{p}$ value $<0,05$ Ha diterima dan Ho ditolak berarti ada hubungan. Untuk mengetahui keeratan hubungan antara dua variabel dapat dilihat pada kolom Correlation Coefficient yaitu 0,270 dan keeratan hubungannya dikategorikan cukup.

\section{Pembahasan}

Hasil penelitian menunjukkan kecemasan yang terjadi pada mahasiswa dalam menghadapi tugas akhir yaitu cemas ringan ada $38.3 \%$, cemas sedang ada $8.5 \%$. ini menunjukkan bahwa kecemasan sangat mengganggu, hal ini bahwa kecemasan pada mahasiswa itu ada saat menghapi tugas akhir.Menurut Keliat (2011), kecemasan adalah suatu rasa tidak nyaman akibat perasaan yang teralalu khawatir timbul perasaan buruk dan disertai tanda gejala fisik seperti keringat dingin, jantung berdebar dan gemetaran. Kecemasan adalah sesuatu yang berkaitan dengan perasaan yang tidak berdaya dan tidak pasti biasanya berkaitan dengan kekhawatiran yang menyebar. Pada hasil penelitian ini didapatkan bahwa responden dengan kategori kecemasan berat yang memungkinkan individu untuk berfokus pada hal yang penting dan tidak menghiraukan hal lain serta mempersempit persepsi individu. Kecemasan biasanya akan secara subjektif dialami dan dapat dikomunikasikan dengan interpersonal (Stuart, 2006). Meskipun dampak dari kecemasan itu negatif yang dialami setiap individu tetapi akan 
ada gejala-gejala spesifik kecemasan lainnya yang dapat menggangu kehidupan sehari-hari. Dalam hal ini tentu diharapkan adanya penanggulangan gejala-gejala kecemasan agar mahasiswa dalam menjalani aktifitasnya di rumah maupun di masyarakat tidak terganggu. Hasil penelitian jugamenunjukkantersebut memperlihatkan motivasi pada mahasiswa S1 Keperawatan, Fakultas Ilmu Keperawatan Universitas Islam Sultan Agung pada mahasiswa tingkat Akhir, sebagian besar mengalami motivasi yang kategorinya baik dengan jumlah 53 responden (56.4\%), sedangkan kategori buruk sebanyak 0 mahasiswa (0\%).Motivasi adalah suatu dorongan pada individu dalam belajar untuk menggapai hasil yang maksimal. Motivasi dapat dikatakan sebagai penggerak untuk melakukan suatu kegiatan untuk menggapai tujuan yang diinginkan. Seseorang yang memiliki motivasi belajar yang kuat akan menghadapi tugas dengan tabah dan penuh semangat (Sardiman, 2010).

Motivasi sangat penting untuk mahasiswa, hal ini sangat dibutuhkan mahasiswa agar semua kegiatan atau tugas yang didapatkan menjadi lebih baik dan selesai dengan tepat. Tergambar pada hasil penelitianmotivasi pada mahasiswa S1 Keperawatan tingkat akhir yaitu kategorinya baik dengan jumlah 53 mahasiswa (56.4\%), sedangkan yang motivasinya dengan kategori cukup sebanyak 41 mahasiswa (43.6\%). Motivasi merupakan suatu dorongan yang ada dalam jiwa seseorang untuk melakukan kegiatan yang akan menghasilkan hasil yang positif (Sardirman, 2010). Penelitian ini sejalan juga dengan penelitian yang dilakukan Luqman (2013) menyatakan motivasi diperlukan saat mengahadapi sesuatu agar individu tidak mengalami kecemasan, sehingga motivasi sangat berhubungan dengan kecemasan, dengan nilai koefisien korelasi (r) sebesar -0,518 dan nilai significacy (p) sebesar 0,000 yang dilakukan di Fakultas Kedokteran Universitas Sebelas Maret Surakarta. Kecemasan adalah rasa takut yang menyebar pada diri seseorang atau rasa takut melakukan sesuatu (Djuazi, 2010).

Hasil dari analisis yang telah dilakukan menunjukkan bahwa 66\% mahasiswa yang mempunyai motivasi baik tidak mengalami kecemasan dan 53\% mahasiswa yang mempunyai motivasi cukup mengalami kecemasan ringan, hal ini telah tergambar pada hasil penelitian.Sedangkan untuk ada Uji spearman didapatkan data bahwa terdapat hubungan antara motivasi dengan kecemasan mahasiswa tingkat akhir dengan melihat nilai p-value atau Sig. yaitu 0,009 atau p-value < 0,05 p value < 0,05 yang menyatakan ada hubungan. Untuk mengetahui keeratan hubungan antara dua variabel dapat dilihat pada kolom Correlation Coefficient, yaitu 0,270 dan keeratan hubungannya dikategorikan cukup. Hasil penelitian ini 
sejalan dengan penelitian yang dilakukan oleh penelitian sebelumnya didapatkan nilai koefisien korelasi (r) sebesar -0,518 dan didapatkan nilai significacy (p) sebesar 0,000 di fakultas kedokteran universitas sebelas maret surakarta (Luqman, 2013).

Motivasi mempengaruhi kecemasan karena hasil yang didapatkan pada motivasi baik dan cukup lebih banyak yang tidak mengalami kecemasan, daripada yang mengalami kecemasan ringan dan kecemasan sedang. Dari 94 responden yang mengalami kecemasan berdasarkan pengisian kuesioner bahwa sebagian besar mengalami tidak ada cemas yaitu sebanyak 50 responden $(53.4 \%)$, sedangkan cemas berat sekali juga ada 0 mahasiswa (0\%). Penelitian ini sejalan dengan penelitian Paramita dan Wulandari (2013). Hasil penelitian ini memperoleh bahwa siswa rentang mengalami kecemasan. Dari 50 responden didapatkan 30 responden $(82,9)$ tidak mengalami kecemasan. Kejadian ini biasanya disebabkan oleh faktor fisik, sosial, dan psikis.

Hal ini menurut Yusuf (2011) menunjukkan ada peran mediational dari efikasi diri secara langsung dan tidak langsung pada motivasi berprestasi dan strategi pembelajaran. DeCaro dan Johnson (2015) menyatakan bahwa orientasi penguasaan pembelajaran yang lebih tinggi dikaitkan dengan peningkatan ketergantungan pada strategi pemecahan masalah yang baik selama eksplorasi dan meningkatkan pembelajaran konseptual. Lin, Chen, dan Nien (2014) menyatakan bahwa strategi belajar secara e-learning lebih meningkatkan motivasi mahasiswa. Walaupun secara akademik tidak memiliki perbedaan yang berarti. Fungsi motivasi menurut Sardiman (2005) ada tiga fungsi, yaitu: 1) Menyeleksi perbuatan, 2) Mendorong manusia untuk berbuat, 3) Menentukan arah perbuatan.

Fernald yang dikutip oleh Fasti Rola (2006) dalam Anik Widiastuti (2007) menyatakan ada empat fakor yang berpengaruh terhadap motivasi bagi seseorang, yaitu: 1) Pengaruh kebudayaan dan keluarga (cultural influences and family), 2) Peranan dari konsep diri (role of self concept), 3) Pengaruh dan peran jenis kelamin (influence of sex role), dan 4) Pengakuan dan prestasi (recognition and archievement). Dimyati (2006) menjelaskan tentang faktor yang mempengaruhi motivasi belajar, yakni aspirasi atau cita-cita, kondisi jiwa, kondisi lingkungan, dan kemampuan. Motivasi sangat penting untuk setiap individu karena untuk membangun percaya diri dan melakukan sesuatu. 


\section{Kesimpulan}

Terdapat hubungan motivasi mahasiswa terhadap tingkat kecemasan mahasiswa yang sedang menjalani tugas akhir. Separuh lebih responden mempunyai motivasi baik dan tidak mengalami kecemasan.

\section{Saran}

Bisa dilakukan penelitian lebih lanjut terkait motivasi mahasiswa dan kecemasan mahasiswa menghadapi tugas akhir, melihat faktorfaktor yang mempengaruhi motivasi mahasiswa dalam tugas akhir. Dapat juga dilakukan terkait metode pembelajaran yang dapat digunakan dalam menjalankan tugas akhir.

\section{Daftar Pustaka}

Cheryl. (2010). Anxiety. California: ABC-CLIO.

DeCaro, D.A., DeCaro M.S. Johnson, B.R. (2015). Achievement motivation and knowledge development during exploratory learning.Learning andIndividual Differences, 37,1326.

Gunarsa, Singgih. (2008). Psikologi Praktis: Anak, Remaja, keluarga. Jakarta: Gunung Mulia. Hamalik, Oemar. (2011). Kurikulum dan Pembelajaran. Jakarta: Bumi Aksara.

Hawari, D.(2011). Pskiatri Manajemen Stress, Cemas\& Depresi. Jakarta: FK UI.

Hendri, Jhon. (2009). Riset Pemasaran. Merancang Kuesioner. Universitas Gunadarma.

Hidayat, A. A. A. (2007). Metode PenelitianKeperawatandan Teknik Analisa Data. Jakarta: Salemba Medika.

Hoetomo. (2005). Kamus Lengkap Bahasa Indonesia. Surabaya: Mitra Pelajar. Hungu.(2007).Demografi kesehatan Indonesia.Jakarta: Penerbit Grasindo.

Ilyas, Yasis.(2011)., Penilaian Kinerja Teori, dan Penelitian.Depok: PusatKajian Ekonomi Kesehatan FKM UI.

Jonathan, Sarwono. (2006).Metode Penelitian Kuantitatif dan Kualitatif.Yogyakarta:Graha Il.

Keliat, W.A.P. (2011). Manajemen kasus gangguan jiwa: CMHN (Intermediate Course). Jakarta: EGC.

Lin, H.M., Chen, W.J., \& Nien, S.F. (2014). The Study of Achievement and motivation by eLearning-A case study.International Journal of Information and Education Technology, 4 (5), 421-425.

Naderi, H., Abdullah, R., Aizan, T., Sharir, J., \& Kumar, T. (2009). Self esteem, gender and academic achievement of undergraduate students. American Journal of Scientific Research, 3, 26-37.

Notoatmodjo. (2010). Metodologi Penelitian Kesehatan. Jakarta: Rineka Cipta.

Nursalam. (2013). Metodologi Penelitian Ilmu Keperawatan: Pendekaatan Praktis Edisi ketiga. Jakarta: Salemba Medika.

P. Robbins, Stephen. (2008).Organizational Behaviour, Tenth Edition (Perilaku Organisasi Edisi ke Sepuluh), Alih Bahasa Drs.Benyamin Molan. Jakarta: Salemba Empat.

Papalia, D.E., Old, S.W., dan Feldman, R.D.(2008). Human Development (Psikologi Perkembangan). Jakarta:Kencana. 
Paramita dan Wulandari (2013). Hubungan Antara Kecemasan Dengan Motivasi Berprestasi Dalam Menghadapi Ujian Nasional Pada Siswa SMAN Unggulan Berdasarkan Nilai UN Di DKI Jakarta. Jakarta: Universitas Bina Nusantara.

Ramaniah. (2008). Kecemasan: Bagaimana Mengatasi Penyebabnya. Jakarta: Pustaka Obor.

Sardiman, A. M. (2011). Interaksi dan Motivasi Belajar Mengajar. Jakarta: PT. Raja Grafindo Persada.

Semium, Yustinus. (2010). Kesehatan Mental 2. Yogyakarta: Kanisius.

Slameto. (2010). Belajar Dan Faktor-faktor Yang Mempengaruhinya. Jakarta: Rineka Cipta.

Stuart, dkk (2006),Buku Saku Keperawatan Jiwa,Edisi 3 Jakarta :EGC.

Stuart, G. W. (2007).Buku Saku Keperawatan Jiwa. Edisi 5. Jakarta. EGC.

Sugiharto. (2011). Pengertian Aktivitas Belajar. Jakarta: Bumi Aksara.

Sugiyono. (2010). Metode Penelitian Pendidikan Pedekatan Kuantitati, Kualitatif, dan R\&D. Bandung: ALFABETA.

Taylor. (2010). Comprehensif Perioperative Nursing. Jakarta: EGC.

Tahrekhania, M., \& Sadeghian, Z. (2015). Intrinsic Motivation Comparative Investigation between Nursery, Midwifery, and Medicine Students During Internship in Iran. Elsevier, 185-189.

Uno, H. B. (2011). Teori Motivasi dan pengukurannya. Jakarta: PT. Gramedia.

Uno, H. B. (2016). Teori Motivasi dan Pengukurannya. Jakarta: Bumi Aksara.

Viedback. S,J. (2008). Buku Ajar Jiwa, Jakarta: EGC.

Yusuf, M. (2011). The impact of self-efficacy, achievement motivation, and selfregulated learning strategies on students' academic achievement.Procedia Social and Behavioral Sciences, 15, 2623-2626. 